\title{
CHARACTERISTIC GROWTH PROCESSES OF ICE CRYSTALS ON THE ANTARCTIC ICE SHEET
}

\author{
by
}

Hiroshi Nishimura

(MTS Institute Inc., Maritime Building, 14-7, Sanbancho Chiyoda-ku, Tokyo 102, Japan)

and

Norikazu Maeno

(Institute of Low Temperature Science, Hokkaido University, Nishi 8, Kita 19, Sapporo 060, Japan)

\section{ABSTRACT}

Characteristic growth processes were investigated by measuring cross-sectional areas of ice crystals for four $30 \mathrm{~m}$ snow cores drilled in Mizuho Plateau, Antarctica. Considerable difference was found in the growth rate of crystals between a temperature-gradient layer above $6 \mathrm{~m}$ depth and an isothermal layer below $10 \mathrm{~m}$ depth: the growth rate in the temperature-gradient layer was much larger than that in the isothermal layer. In the isothermal layer, temperature dependence of the growth rate $K$ was expressed by an equation $K=K_{0} \exp (-E / R T)$, where $R$ and $T$ are the gas constant and absolute temperature respectively. The apparent activation energy $E$ is $44.7 \mathrm{~kJ} \mathrm{~mol}^{-1}$.

On the other hand, in the temperature-gradient layer. the apparent activation energy was as small as $12 \mathrm{~kJ} \mathrm{~mol}^{-1}$. the difference was explained as due to the temperature gradient. Using the temperature profiles in snow that have been estimated from the meteorological data from several stations, the growth rates in the temperature-gradient layer were calculated. The calculated temperature dependence of the growth rates, taking into consideration vertical flux of water vapor between ice particles caused by the temperature gradient, showed good agreement with measured results. It is concluded that the growth process in the layer above $6 \mathrm{~m}$ depth is mainly due to vapor transport under the vertical temperature gradient.

\section{INTRODUCTION}

Snow deposited on polar regions densifies and undergoes a change in structure and physical properties. During the densification, which is usually accompanied by a sintering process, ice crystals in snow grow in size. Measurements of such crystal growth have been made by many authors for different types of snow in Antarctica and Greenland: Stephenson (1967) and Gow (1969) demonstrated a close relationship between the growth rate and temperature which was similar to that in a sintering process of ceramic materials under isothermal conditions.

In a surface-snow layer in polar regions, however, there are often large vertical temperature gradients, which result in a considerable amount of vertical transport of water vapor. Consequently, the crystal growth there is expected to be quite different from that which occurs under isothermal conditions. Such a discrepancy, between the growth rate of the isothermal layer and the temperaturegradient layer, has been found by Nakaya and Kuroiwa (1967) at Site 2 in Greenland, and by Gow (1969) at South Pole Station in Antarctica.

Various authors (e.g. de Quervain 1958, Akitaya 1974) have studied the crystal growth in the temperature-gradient layer in seasonal snow fields and laboratories, but the details of the growth processes in the temperature-gradient layer in polar regions were not investigated.
In the present study, crystal size in snow was measured in $30 \mathrm{~m}$ snow cores that had been drilled at four sites on Mizuho Plateau, East Antarctica, and regional difference in the crystal-growth process was examined with special reference to the temperature-gradient layer.

\section{CORING SITES AND MEASURING METHODS}

The samples used for the measurements were the four $30 \mathrm{~m}$ snow cores, which were also used for the measurement of densities (Nishimura and others 1983), air permeabilities and specific areas of internal free surfaces (Nishimura and Maeno 1984, 1985). The cores were drilled at the four sites shown in Figure 1: S18 $\left(69^{\circ} 02^{\prime} \mathrm{S}, \quad 40^{\circ} 07^{\prime} \mathrm{E}\right), \mathrm{W}^{\prime} 200$ $\left(69^{\circ} 35^{\prime} \mathrm{S}, 48^{\circ} 50^{\prime} \mathrm{E}\right)$, U234 (71 $\left.01^{\circ} \mathrm{S}, 47^{\circ} 29^{\prime} \mathrm{E}\right)$ and V142 $\left(72^{\circ} 32^{\prime} \mathrm{S}, 51^{\circ} 57^{\prime} \mathrm{E}\right)$. Snow temperatures at $10 \mathrm{~m}$ depth are $-15.9^{\circ} \mathrm{C}$ at $\mathrm{S} 18,-33.1^{\circ} \mathrm{C}$ at $\mathrm{W}^{\prime} 200,-38.5^{\circ} \mathrm{C}$ at U234 and $-48.1^{\circ} \mathrm{C}$ at V142; these are considered to be close to the mean annual air temperatures at each site. Mean annual accumulation rates of snow were estimated from stratigraphic analyses of the cores as $210 \mathrm{~kg} \mathrm{~m}^{-2} \mathrm{a}^{-1}$ at $\mathrm{S} 18$, $290 \mathrm{~kg} \mathrm{~m}^{-2} \mathrm{a}^{-1}$ at $\mathrm{W}^{\prime} 200, \quad 190 \mathrm{~kg} \mathrm{~m}^{-2} \mathrm{a}^{-1}$ at U234 and $90 \mathrm{~kg} \mathrm{~m}^{-2} \mathrm{a}^{-1}$ at $\mathrm{V} 142$.

Vertical thin sections of snow were prepared by cutting aniline-reinforced samples. Thin sections planed to thicknesses about $0.2-0.4 \mathrm{~mm}$ were photographed under polarized light. Mean cross-sectional areas of individual ice crystals were measured in photographs roughly $20 \mathrm{~mm} \times$ $14 \mathrm{~mm}$ in area.

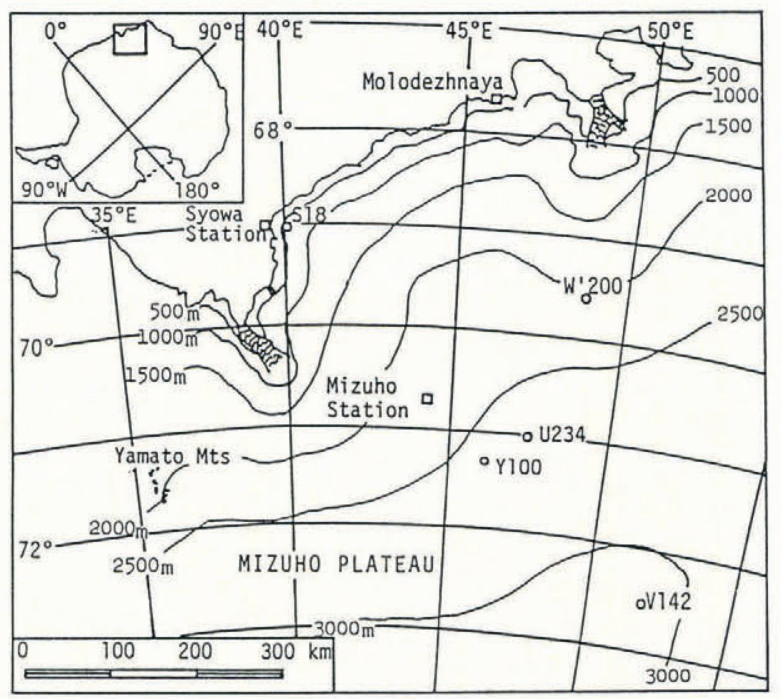

Fig. 1. Map of Mizuho Plateau, showing locations of core-sampling sites (S18, W'200, U234, V142), represented by open circles. 


\section{RESULTS}

Mean cross-sectional areas of crystals at the four sites are plotted against depth in Figure 2; they increase with depth, showing large rates of increase at more than $6 \mathrm{~m}$

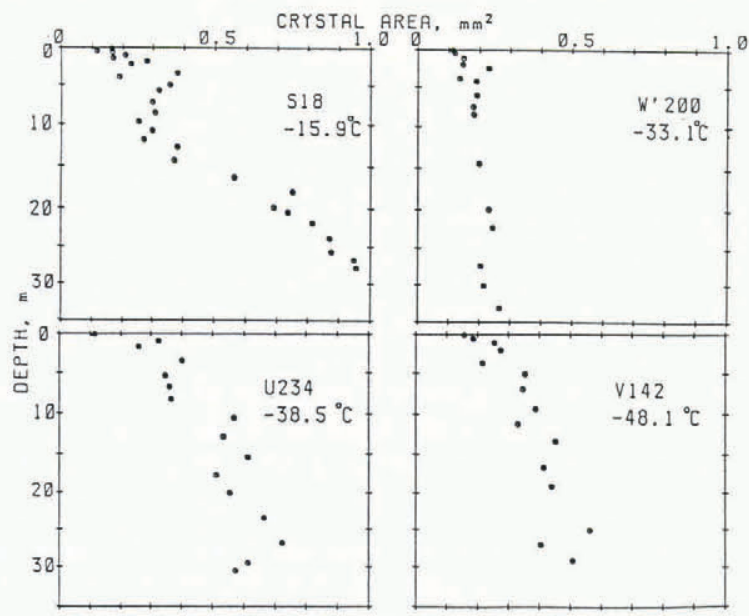

Fig. 2. Mean value of cross-sectional areas of ice crystals, plotted against depth at S18, W'200, U234 and V142.

depth at the four sites. The overall tendency is similar to that found at South Pole Station (Gow 1969).

Figure 3 shows relations between the crystal areas and pressure of overburden snow at the four sites; pressures were calculated from the density-depth relations of the cores (Nishimura and others 1983). It should be noted that each relation between the crystal area and pressure is expressed roughly by two straight lines. The rates of increase are greater in shallower layers, less than about $3 \times 10^{4} \mathrm{~Pa}$, compared with those in the deeper layers. The pressure of $3 \times 10^{4} \mathrm{~Pa}$ corresponds to depths from 6 to $10 \mathrm{~m}$.

Assuming a constant accumulation rate of snow, the time that had elapsed since deposition at the surface can be estimated from the pressure of overburden snow divided by the mean annual accumulation rate. Then it was found that the crystal area increases linearly with time; the linear relationship is similar to the results obtained by Stephenson (1967) and Gow (1969).
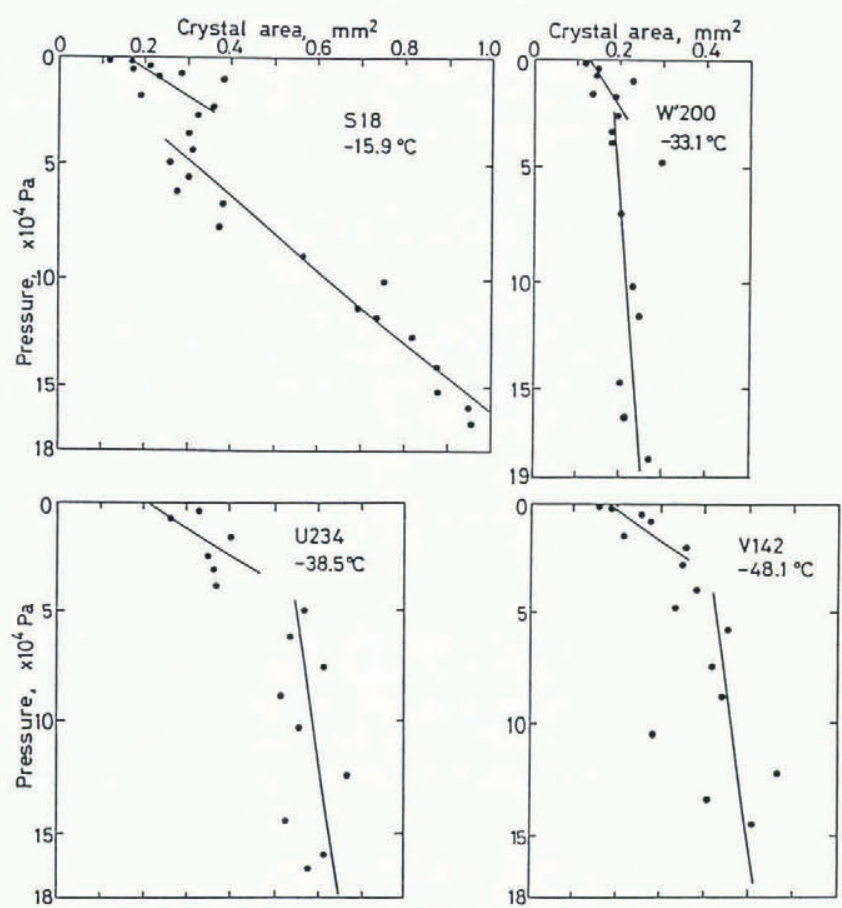

Fig. 3. Mean value of the cross-sectional areas of ice crystals, plotted against overburden pressure at the four sites.

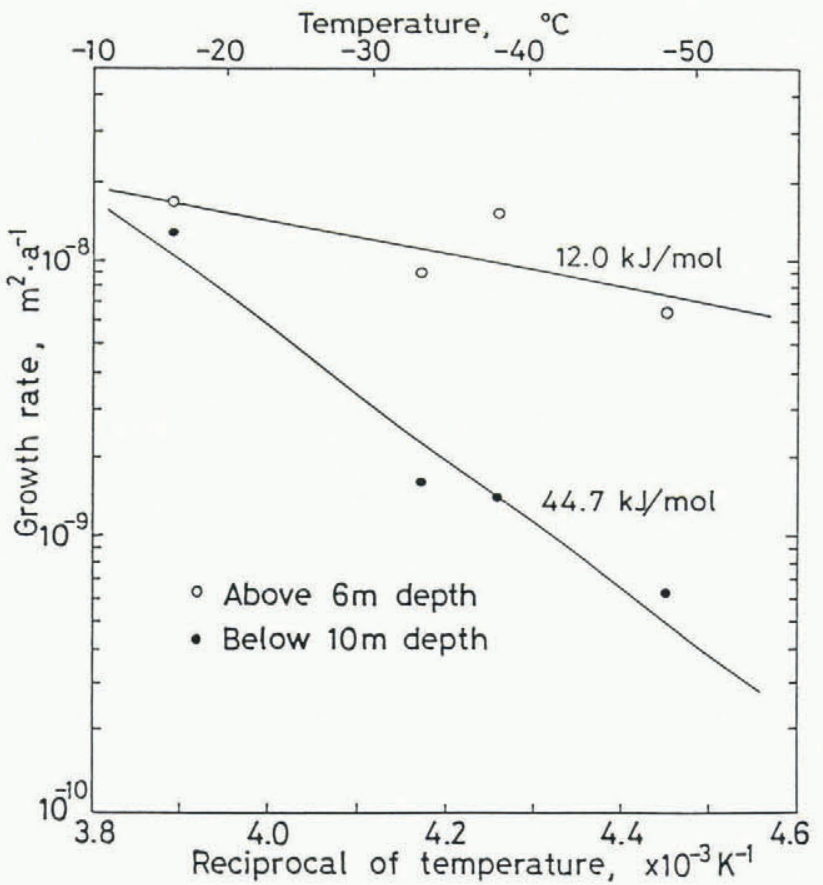

Fig. 4. Relations between the growth rate of the cross-sectional areas of crystals and the reciprocal of temperature in the layer above $6 \mathrm{~m}$ depth (open circles) and below $10 \mathrm{~m}$ depth (solid circles).

Figure 4 shows the relation between the growth rate $K$ and the reciprocal of temperature $1 / T$, where $K$ is the proportionality constant appearing in the linear relation and $T$ is the absolute temperature. In the deeper layer, below $10 \mathrm{~m}$ depth, the growth rate decreases significantly with decreasing temperature. This relation, which is almost like that of Gow (1969), is expressed as

$$
K=K_{0} \exp (-E / R T)
$$

where $K_{0}$ is constant $\left(12.9 \mathrm{~m}^{2} \mathrm{a}^{-1}\right), \quad E \quad$ and $R\left(8.314 \mathrm{~J} \mathrm{~mol}^{-1} \mathrm{~K}^{-1}\right)$ are the apparent activation energy of crystal growth and the gas constant respectively. The activation energy obtained from the slope of the straight line for snow below $10 \mathrm{~m}$ in depth is $44.7 \mathrm{~kJ} \mathrm{~mol}^{-1}$, which is slightly smaller than the value of $48.6 \mathrm{~kJ} \mathrm{~mol}^{-1}$ given by Gow (1969).

In the surface layer above about $6 \mathrm{~m}$ depth, the apparent activation energy is extremely small - almost four times smaller: $E=12.0 \mathrm{~kJ} \mathrm{~mol}^{-1}$ and $K_{0}=4.7 \times 10^{-6} \mathrm{~m}^{2} \mathrm{a}^{-1}$. This result suggests that the growth processes of crystals are different in the layers above $6 \mathrm{~m}$ and those below $10 \mathrm{~m}$. In the deep layer, below about $10 \mathrm{~m}$, it is considered to be an isothermal crystal-growth process, but in the surface layer, above $6 \mathrm{~m}$, it seems to be necessary to take account of the effect of the temperature gradient, since polar snow in a surface layer above $6 \mathrm{~m}$ depth is usually subject to a large temperature gradient (Nishimura and Maeno 1984). In the following we try to explain the small apparent activation energy in the surface layer by the effect of the vertical temperature gradient in snow.

\section{THERMAL CONDITION IN SNOW}

In Antarctica amplitudes of annual variations in air temperatures are usually greater in the interior regions than in the coastal regions. According to Nishimura and Maeno (1984), the amplitude of annual variations in air temperatures $A_{\mathrm{a}}$ in Antarctica, which is defined as half the difference between the maximum and minimum of monthly mean air temperatures, is described by the mean annual air temperature $\bar{\theta}_{\mathrm{ao}}$ as

$$
A_{\mathrm{a}}=6.69 \exp \left(-0.0192 \bar{\theta}_{\mathrm{ao}}\right)
$$


Using this equation, $A_{\mathrm{a}}$ at the four sites are estimated to be $9.1^{\circ} \mathrm{C}$ at S18, $12.7^{\circ} \mathrm{C}$ at $\mathrm{W}^{\prime} 200,14.1^{\circ} \mathrm{C}$ at U234, and $16.9^{\circ} \mathrm{C}$ at $\mathrm{V} 142$.

Diurnal temperature variations also differ among the four sites. Like the amplitude of annual variations in air temperature, the average amplitudes of diurnal temperature variations $A_{\mathrm{d}}$ are also related to the mean annual air temperature ${ }^{\mathrm{\theta}} \overline{\mathrm{a}}_{\mathrm{o}}$, which is expressed as the following equation:

$$
A_{\mathrm{d}}=2.60 \exp \left(-0.015 \bar{\theta}_{\mathrm{ao}}\right)
$$

Estimated values of $A_{\mathrm{d}}$ are $3.3^{\circ} \mathrm{C}$ at $\mathrm{S} 18,4.3^{\circ} \mathrm{C}$ at W'200, $4.6^{\circ} \mathrm{C}$ at $\mathrm{U} 234$, and $5.3^{\circ} \mathrm{C}$ at $\mathrm{V} 142$.

We assume that the surface temperature $\theta_{0}$ of a snow layer changes with time $t$ as

$$
\theta_{0}=\bar{\theta}_{0}+A \cos (2 \pi t / \lambda)
$$

where $\lambda$ is the period, and $A$ and $\bar{\theta}_{0}$ are the amplitude and mean temperature of the snow surface respectively. Then the temperature at a depth $z$ is given from a common theory of thermal conduction (Carslaw and Jaeger 1967):

$$
\theta=\bar{\theta}_{0}+A \exp \left\{-z(\pi / a \lambda)^{\frac{1}{2}}\right\} \cos \left\{(2 \pi t / \lambda)-z(\pi / a \lambda)^{\frac{1}{2}}\right\}
$$

where $a$ is the thermal diffusivity of snow.

The temperature gradient in snow at a depth $z$ is given by differentiation of Equation (5):

$$
\begin{gathered}
\mathrm{d} \theta / \mathrm{d} z=-A(\pi / a \lambda)^{\frac{1}{2}} \exp \left\{-z(\pi / a \lambda)^{\frac{1}{2}}\left[\cos \left\{(2 \pi t / \lambda)-z(\pi / a \lambda)^{\frac{1}{2}}\right\}+\right.\right. \\
\left.+\sin \left\{(2 \pi t / \lambda)-z(\pi / a \lambda)^{\frac{1}{2}}\right\}\right]
\end{gathered}
$$

Assuming that the mean annual temperature of the snow surface is identical with the mean annual air temperature, we can obtain the temperature and temperature gradient in snow by Equations (5) and (6) respectively. Summing up the profiles for the annual and diurnal variations, the temperature profiles in the snow layer are obtained as shown in Figure 5. This figure shows examples from three seasons at V142.

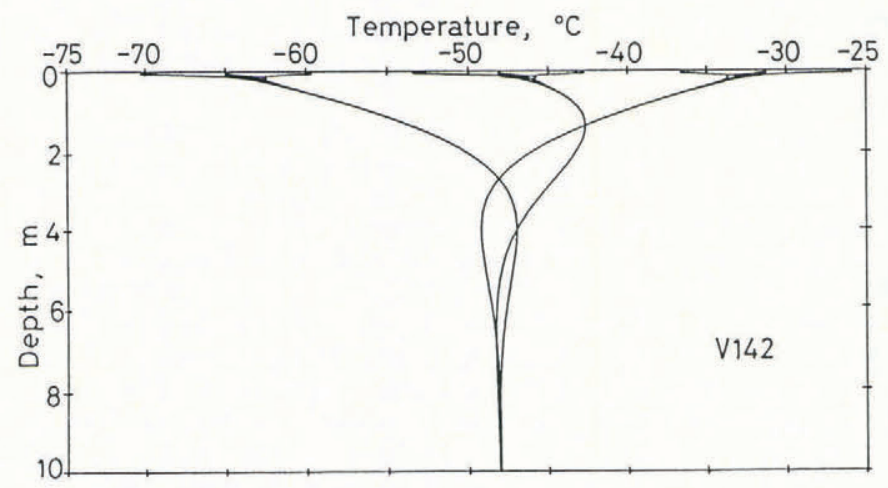

Fig. 5. Examples of temperature profiles for three different seasons, calculated for annual and diurnal variation.

\section{CRYSTAL GROWTH IN THE TEMPERATURE- GRADIENT LAYER}

To discuss the growth of ice particles in the temperature-gradient layer, we assume a simple arrangement of particles as shown in Figure 6. Cubic ice particles with a side length of $a$ are arranged vertically with an interval of $\ell-a, \ell$ being the distance between the centers of the particles; temperature gradient $T^{\prime}$ is applied vertically, the temperature being higher at lower levels. Since ice is a

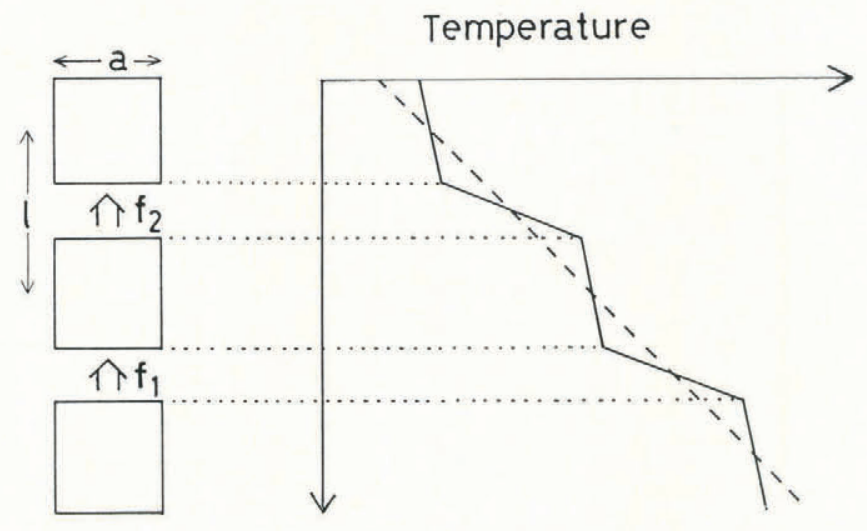

Fig. 6. Idealized particle arrangement and schematic profiles of average temperature in snow (broken line) and local temperature in the particles and spaces (solid line).

much better conductor of heat than air, the temperature gradient in ice particles is smaller than the average temperature gradient of snow $T^{\prime}$. The temperature gradient in ice particles is described as

$$
\left[\frac{\mathrm{d} T}{\mathrm{~d} z}\right]_{\text {ice }}+\frac{k_{\mathrm{s}}}{k_{\mathrm{i}}} T^{\prime}
$$

where $k_{\mathrm{s}}$ and $k_{\mathrm{i}}$ are the thermal conductivities of snow and ice respectively. The temperature gradient in air space between ice particles $\mathrm{d} T / \mathrm{d} z$, which is larger than that of snow, is expressed as

$$
\frac{\mathrm{d} T}{\mathrm{~d} z}=\alpha \mathrm{T}^{\prime}
$$

where

$$
\alpha=\frac{-a\left(k_{\mathrm{s}} / k_{\mathrm{i}}\right)}{\ell-a}
$$

When we assume that air in the pore space of snow is saturated by water vapor, the flux of water vapor between ice particles $f$ is given by

$$
f=-D \frac{\mathrm{d} \rho \mathrm{v}}{\mathrm{d} z}
$$

where $\rho_{\mathrm{y}}$ is the saturated density of water vapor. $D$ is the diffusion coefficient of water vapor given by the following equation (Hall and Pruppacher 1977):

$$
D=x\left(T / T_{0}\right)^{y} \quad\left(\mathrm{~m}^{2} \mathrm{~s}^{-1}\right)
$$

where $x=2.11 \times 10^{-5}\left(P_{a 0} / P\right)$ and $y=1.94 . \quad P$ is air pressure, $P_{\mathrm{ao}}=1.013 \times 10^{5} \mathrm{~Pa}$, and $T_{0}=273 \mathrm{~K}$.

The value of $\rho_{\mathrm{y}}$ on the ice surface is obtained from the Clausius-Clapeyron equation as

$$
\rho_{\mathrm{v}}=\frac{M P_{0}}{R T} \exp \left\{\frac{L}{R}\left(\frac{1}{T_{0}}-\frac{1}{T}\right)\right\}
$$

where $P_{0}$ is the saturated vapor pressure at temperature $T_{0}$, $M$ is the molecular weight of water, and $R$ and $L$ are the gas constant and latent heat of the sublimation of ice respectively. Equation (12) can be rewritten with good approximation in the temperature region of the problem as

$$
\rho_{\mathrm{v}}=\frac{A}{R T} \exp \left\{B\left(T-T_{0}\right)\right\}
$$

where $A=M P_{0}$ and $B=L / R T_{0}^{2}$

The gradient of vapor density $\mathrm{d} \rho_{\mathrm{v}} / \mathrm{d} z$ is given by 


$$
\frac{\mathrm{d} \rho_{\mathrm{v}}}{\mathrm{d} z}=\frac{\mathrm{d} \rho_{\mathrm{v}}}{\mathrm{d} T} \frac{\mathrm{d} T}{\mathrm{~d} z}=\frac{\mathrm{d} \rho_{\mathrm{v}}}{\mathrm{d} T} \alpha T^{\prime}
$$

Then the flux between ice particles is given by

$$
f=-D \frac{\mathrm{d} \rho_{\mathrm{v}}}{\mathrm{d} T} \alpha T^{\prime}
$$

The vapor density over the bottom surface of a particle is smaller than that over the upper surface of the lower neighbor. Then water vapor is transported upward according to Equation (15). The ice particle grows at the bottom and sublimes at the top. When we assume that the vapor flux between ice particles given by Equation (15) is supplied by water vapor from the upper surface of the particle and that the vapor is condensed on the bottom surface of the higher neighbor, the growth rate $K$ of the particle for the cross-sectional area is given by

$$
K=\frac{a}{\rho_{\mathrm{i}}}\left(f_{1}-f_{2}\right)=\frac{a}{\rho_{\mathrm{i}}} \frac{\mathrm{d} f}{\mathrm{~d} z} l
$$

where $f_{1}$ and $f_{2}$ are the fluxes between particles in the lower and upper spaces of the particle. As the difference in temperature gradients $T^{\prime}$ between the upper and the next lower spaces can be negligible, the growth rate is expressed as

$$
K=\frac{a \ell}{\rho_{\mathrm{i}}}\left(\frac{y-1}{T}+B\right] x\left[\frac{T}{T_{\mathrm{o}}}\right)^{y} \frac{A B}{R T} \exp \left\{B\left(T-T_{0}\right)\right\} \alpha^{2} T^{\prime 2}
$$

Because $B \gg(y-1) / T$, Equation (17) can be simplified to

$$
K=\frac{a \ell}{\rho_{\mathrm{i}}} x\left[\frac{T}{T_{0}}\right]^{y} \frac{A B}{R T} \exp \left\{B\left(T-T_{0}\right)\right\} \alpha^{2} T^{\prime 2}
$$

This equation shows that the growth rate $K$ is related to temperature $T$, temperature gradient $T^{\prime}$, and $a \ell \alpha^{2} . \alpha$ is also a function of the structural parameters of snow, $\ell$ and $a$ as expressed by Equation (9). The values of $a, \ell, k_{\mathrm{s}} / k_{\mathrm{i}}$, and $a \ell \alpha^{2}$ at the four coring sites are given in Table I. In the

TABLE I. STRUCTURAL PARAMETERS IN THE LAYER ABOVE $6 \mathrm{~m}$ DEPTH AT THE FOUR SITES

\begin{tabular}{l|llll}
\hline $\begin{array}{l}\text { Site } \\
\text { Parameter }\end{array}$ & S18 & W'200 & U234 & V142 \\
\hline$a(\mathrm{~mm})$ & 0.474 & 0.392 & 0.538 & 0.522 \\
$\ell(\mathrm{mm})$ & 0.670 & 0.574 & 0.771 & 0.789 \\
$k_{\mathrm{s}} / k_{\mathrm{i}}$ & 0.282 & 0.228 & 0.249 & 0.204 \\
$\alpha$ & 2.74 & 2.66 & 2.73 & 2.56 \\
$a \ell \alpha^{2}\left(\mathrm{~mm}^{2}\right)$ & 2.38 & 1.59 & 3.10 & 2.70 \\
\hline
\end{tabular}

present calculations, the value of $a$ was assumed to be the length of the side of a square with the same area as a mean cross-sectional area of ice crystals in the layer above $6 \mathrm{~m}$ depth. The value of $\ell$, which is also the mean value in the layer above $6 \mathrm{~m}$ depth, is calculated by using a relation $\ell^{2}\left(\rho / \rho_{\mathrm{i}}\right)=a^{2}$, where $\rho$ is snow density. The ratio $k_{\mathrm{S}} / k_{\mathrm{i}}$ was obtained by using the value $k_{\mathrm{i}}=2.48 \mathrm{~J} \mathrm{~m}^{-1} \mathrm{~s}^{-1}{ }^{\circ} \mathrm{C}^{-1}$, and the values of $k_{\mathrm{s}}$ were obtained by the calculation (Nishimura and Maeno 1984). The values of $a \ell \alpha^{2}$ at the four sites lie in the range from $1.59 \mathrm{~mm}^{2}$ to $3.10 \mathrm{~mm}^{2}$.

Equation (18) was elevated at time steps of $1 \mathrm{~h}$ for the diurnal variation and $10 \mathrm{~d}$ for the annual one. The mean growth rates obtained for cross-sectional areas in the layer above $6 \mathrm{~m}$ depth at the four sites are represented in Figure 7 by open circles; measured values, represented by solid circles, are also shown. The calculated relation between the growth rates and temperature gives a smaller value for the apparent activation energy: $5.6 \mathrm{~kJ} \mathrm{~mol}^{-1}$, quite comparable to the observed value.

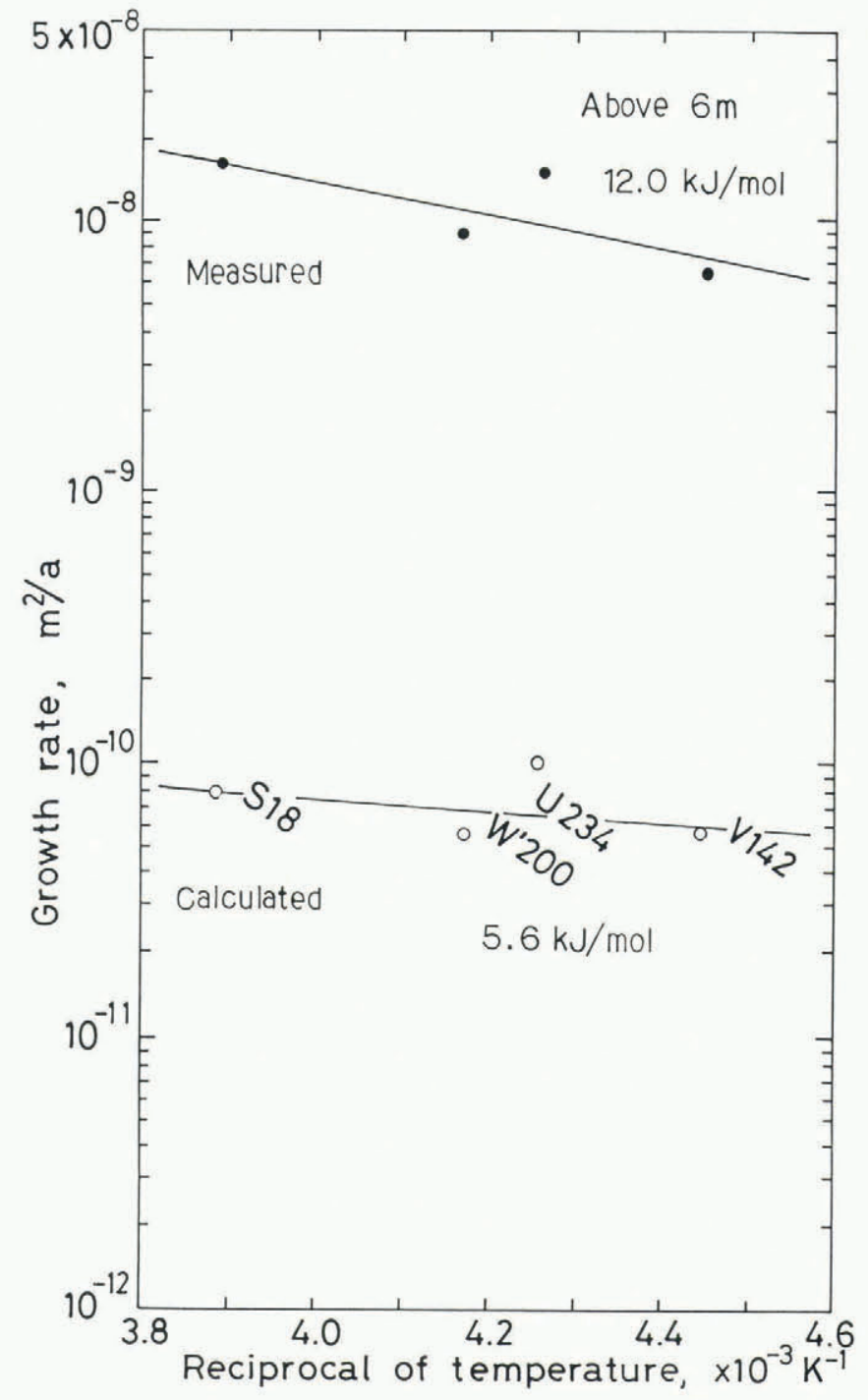

Fig. 7. Relation between the growth rate of the cross-sectional areas and the reciprocal of temperature in the layer above $6 \mathrm{~m}$ depth. Calculated mean growth rates $K$ are represented by open circles; solid circles indicate measured results (Fig. 4).

From the theoretical calculation, it is clear that the small value of the apparent activation energy is determined mainly by the existence of temperature gradients at the four sites. Though the value of the activation energy is even smaller than the measured value, $12.0 \mathrm{~kJ} \mathrm{~mol}^{-1}$, it is suggested that the growth process in the layer above $6 \mathrm{~m}$ depth is mainly due to vapor transport under the vertical temperature gradient. But the calculated growth rates are smaller by about two orders of magnitude than the measured growth rates. This difference might be explained by considering the three-dimensional structure, the distribution of the sizes of ice particles and intervals between particles, and so on.

In the temperature-gradient layer, ice particles grow mainly by vertical vapor flux, which results in an anisotropic structure (i.e. a vertically elongated structure); the growth driven by surface energy in an isothermal process is rather weak. The measured results of the growth rates show that the discrepancy in the growth rates in the temperature-gradient layer (above $6 \mathrm{~m}$ depth) and the isothermal layer (below $10 \mathrm{~m}$ depth) is smaller in the regions where there are higher temperatures, and greater at lower temperatures. The growth rates in the temperature-gradient layers at U234 and V142 are considered to be affected significantly by the vertical vapor flux; this view is also supported by the observation that vertically elongated structures were found frequently at U234 and V142 (Nishimura and Maeno 1984). The above result agrees with 
that obtained from the study of regional differences in the development of vertical structure (Nishimura and Maeno 1984). Vertical vapor flux is considered to be a main reason for the regional differences in the development of vertical structure.

\section{ACKNOWLEDGEMENTS}

The authors would like to express their thanks to Professor S. Kobayashi of Niigata University and Dr R. Naruse of the Institute of Low Temperature Science, Hokkaido University, for their valuable discussions. The authors are also grateful to Professors G. Wakahama and Y. Suzuki and to $\operatorname{Dr} \mathrm{T}$. Kuroda of the Institute for their helpful discussions.

\section{REFERENCES}

Akitaya, E. 1974. Studies on depth hoar. Inst. Low Temp. Sci. Contrib., Ser. A., 26.

Carslaw, H.S., and J.C. Jaeger. 1967. Conduction of heat in solids. Second edition. Oxford, Clarendon Press.

Gow, A.J. 1969. On the rates of growth of grains and crystals in south polar firn. J. Glaciol., 8(53), 241-252.

Hall, W.D., and H.R. Pruppacher. 1977. The survival of ice particles falling from cirrus clouds in subsaturated air. J. Atmos. Sci., 33, 1995-2006.
Nakaya, U., and D. Kuroiwa. 1967. Physical properties and internal structure of Greenland snow. In Oura, H., ed. Physics of Snow and Ice. International Conference on Low Temperature Science ... 1966 ... Proceedings. Vol. 1. $P t$ 2. Sapporo, Hokkaido University. Institute of Low Temperature Science, 953-971.

Nishimura, H., and N. Maeno. 1984. Snow structure and depth hoar formation in Mizuho Plateau, Antarctica. Mem. Natl Inst. Polar Res. Special Issue, 34, 137-146.

Nishimura, H., and N. Maeno. 1985. Studies on structures and physical properties of snow on Mizuho Plateau, Antarctica. Ann. Glaciol., 6, 105-107.

Nishimura, H., J. Inoue, and K. Satow. 1982. Meteorological data at Mizuho Station, Antarctica in 1981. JARE Data Rep., 77. (Meteorology 12.)

Nishimura, H., N. Maeno, and K. Satow. 1983. Initial stage of densification of snow in Mizuho Plateau, Antarctica. Mem. Natl Inst. Polar Res. Special Issue, 29, 149-158.

Quervain, M.R. de. 1958. On metamorphism and hardening of snow under constant pressure and temperature gradient. IASH Publ. 46 (General Assembly of Toronto 1957 - Snow and Ice), 225-239.

Stephenson, P.J. 1967. Some considerations of snow metamorphism in the Antarctic ice sheet in the light of ice crystal studies. In Oura, H., ed. Physics of Snow and Ice. International Conference on Low Temperature Science ... 1966 ... Proceedings. Vol. 1, Pt 2. Sapporo, Hokkaido University. Institute of Low Temperature Science, 725-740. 